\title{
Epidemiological Profile of Chronic Kidney Disease at the General Hospital of National Reference of N’Djamena (Chad)
}

\author{
Ibrahim Hamat ${ }^{*}$, Guillaume Mahamat Abderraman'1, Zeinab Maïga Moussa Tondi², \\ Mahamat Youssouf ${ }^{3}$, Mouhammadou Moustapha Cisse ${ }^{4}$, Fotclossou Tara ${ }^{1}$, \\ Elhaj Fary $\mathrm{Ka}^{4}$, Abdou Niang4, Boucar Diouf ${ }^{4}$
}

\author{
${ }^{1}$ Nephrology-Hemodialysis Unit, General Hospital of National Reference of N’Djamena, N’Djamena, Chad \\ ${ }^{2}$ Service of Nephrology, National Hospital of Lamordé of Niamey, Niamey, Niger \\ ${ }^{3}$ Internal medicine, Renaissance Hospital of N'Djamena, N'Djamena, Chad \\ ${ }^{4}$ Service of Nephrology, Aristide Le Dantec Hospital, Dakar, Senegal \\ Email: ^doctahmat@yahoo.fr, zalba2001@yahoo.fr
}

How to cite this paper: Hamat, I., Mahamat Abderraman, G., Moussa Tondi, Z.M., Youssouf, M., Cisse, M.M., Tara, F., Ka, E.F., Niang, A. and Diouf, B. (2016) Epidemiological Profile of Chronic Kidney Disease at the General Hospital of National Reference of N'Djamena (Chad). Open Journa of Nephrology, 6, 78-85. http://dx.doi.org/10.4236/ojneph.2016.63010

Received: August 24, 2016

Accepted: September 16, 2016

Published: September 19, 2016

Copyright $\odot 2016$ by authors and Scientific Research Publishing Inc. This work is licensed under the Creative Commons Attribution International License (CC BY 4.0).

http://creativecommons.org/licenses/by/4.0/

\section{Abstract}

Introduction: Chronic renal failure is a disease that affects many patients worldwide and increasingly in Africa. At the end of 2003, about 1.1 million people were suffering from End-Stage Renal Disease (ESRD) and were treated with periodic dialysis [12]. In Africa, CKF represents $2 \%$ to $10 \%$ of hospital admissions and is responsible for $4 \%$ to $22 \%$ of deaths [14]. So, this study is conducted for the first time in Chad, with the aims to determine the prevalence of CKD. Methods: This was a retrospective, descriptive and analytical study over a period of 12 months from April 29, 2011 to April 28, 2012. All patients with chronic renal failure regardless of etiology and stage of chronic kidney disease were included in the study. Chronic renal failure was defined as a glomerular filtration rate below $60 \mathrm{ml} / \mathrm{min} / 1.73 \mathrm{~m}$ (MDRD) for more than 3 months. This study was conducted in several departments of the National General Reference Hospital (NGRH) of N'Djamena. Result: Among 2039 inpatients, 195 patients had chronic renal failure, as a frequency of $9.6 \%$. The average age of our patients was $51 \pm 16.8$ years, ranging from 11 to 85 years. Male predominance was noted to be $59 \%$ of men against $41 \%$ of women. We noted that high blood pressure accounted for $66.2 \%(\mathrm{~N}=129)$ of cases, diabetes in $48.2 \%(\mathrm{~N}=94)$, alcoholism in $28.7 \%(\mathrm{~N}=56)$, smoking in $14.9 \%(\mathrm{~N}=29)$ and the association alcoholism-smoking in $19.5 \%(\mathrm{~N}=38)$. Hypertension was the leading cause of chronic renal failure (66.2\%). All patients had a serum creatinine and creatinine clearance was assessed. Among them, we noted 57 patients (29\%) with end-stage renal failure. The average calcium and phosphate serum were $1.8 \mathrm{mmol} / \mathrm{l}$ and $1.6 \mathrm{mmol} / \mathrm{l}$, respectively. We 
noted that 120 patients as $61.5 \%$, currently took herbal medicine. 48 out of 57 of our patients with ESRD as $24.6 \%$ of patients in the study had received replacement therapy (hemodialysis) with $12.5 \%$ of deaths. Conclusion: Chad, who compiled the first study with 195 patients at the General Hospital of N'Djamena National Reference over a period of one year has objectified a prevalence of chronic renal failure of $9.6 \%$.

\section{Keywords}

Chronic Kidney Disease, Epidemiology, N'djamena, Chad

\section{Introduction}

Chronic kidney disease is a major public health challenge in terms of social and human costs [1]. The number of patients with chronic kidney disease increased in a major way in the world over the past decade. Worldwide at the end of 2003, about 1.1 million people were suffering from End-Stage Renal Disease (ESRD) and were treated with periodic dialysis [2]. In France, there were 37,430 patients treated by dialysis in 2010 (an increase of $12 \%$ since 2006), a prevalence of 720 per million population [3]. In Africa, CKF represents $2 \%$ to $10 \%$ of hospital admissions and is responsible for $4 \%-22 \%$ of deaths [4]. In Côte d'Ivoire, at the internal medicine department of CHU Treichville, it was the second cause of death with a prevalence of 6.14\% [4]. In Senegal, the hospital incidence is estimated at 87 new cases per year [5]. In Chad, we do not have any statistics on kidney disease. The first unit of Nephrology-Hemodialysis was born in 2011. Kidney diseases are under diagnosed and patients were seen in specialized nephrology consultation at chronic renal failure indeed end stage. That's why we initiated this study whose objectives were to determine the epidemiological profile of patients with chronic renal failure. This study had been conducted within the General Hospital of National Reference in N'Djamena over a period of one year (2011-2012). Level 3 hospital with 260 beds is the biggest hospital in Chad.

\section{Material and Methods}

This was a retrospective, descriptive and analytical study over a period of 12 months from April 29, 2011 to April 28, 2012. Were included in the study, all patients with chronic renal failure regardless of etiology and stage of chronic kidney disease. Chronic renal failure was defined as a glomerular filtration rate below $60 \mathrm{ml} / \mathrm{min} / 1.73 \mathrm{~m}$ (MDRD) for more than 3 months. This study was conducted in several departments of the National General Reference Hospital (NGRH) of N'Djamena: cardiology, infectious disease and nephrology. The NGRH is a national public health reference (level) III facility with a capacity of 260 beds located in the capital N'Djamena, Chad. This is the second reference nephrology department of the country. Nephrology department staff consists of two nephrologists, a general practitioner and three interns. The renal unit further includes a hospitalization sector equipped with 8 beds. The parameters studied 
were epidemiological, clinical, biological and therapeutic. The qualitative variables were represented by gender, occupation, risk factors and clinical signs. Quantitative variables were represented by age, different stages of CKD and biochemical exams: hemoglobin, serum phosphate, serum calcium, uric acid. These data were collected using a survey according to patient records. Some patients have been contacted if their file was incomplete with their prior consent. Were excluded from the study, all patients with acute renal failure and those who didn't give their consent. Data were entered and analyzed using SPSS 18 software and were processed by univariate bivariate analysis.

\section{Results}

During this period, 2039 patients were hospitalized for kidney failure in the various service of the GHNR. Among them, 195 patients had met the inclusion criteria as $9.6 \%$ of cases. The other patients were not selected because they presented acute renal failure which have recovered, had incomplete files or had not or had not given their consent.

\subsection{Sociodemographic Parameters}

\subsubsection{Age}

The average age was $51.8 \pm 16.8$ years and extreme ranging from 11 years to 85 years. The age group between 45 to 64 years accounted for $44.10 \%$ of all cases. Distribution according to ages is summarized in Figure 1.

\subsubsection{Gender}

Our study population consisted of 114 men and 81 women with a sex ratio of 1.4.

\subsection{Clinical Characteristic}

We noted that $54.4 \%$ of patients were hospitalized in cardiology as shown in Figure 2.

\subsubsection{Risk Factors}

We noted that high blood pressure account for $66.2 \%(\mathrm{~N}=129)$ of cases, diabetes

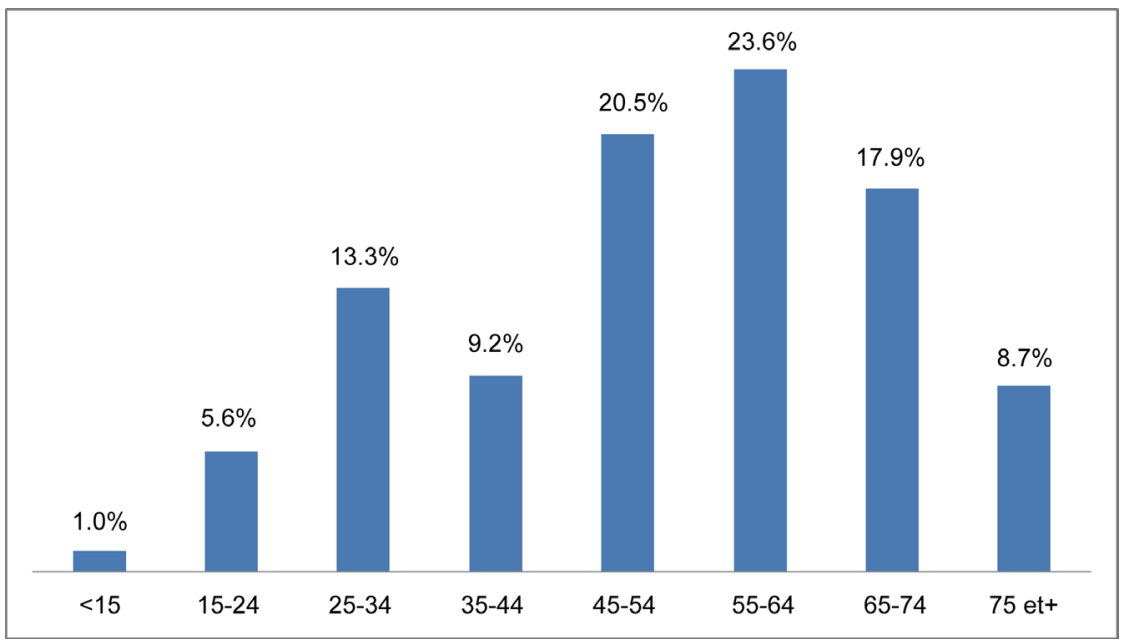

Figure 1. Distribution of patients according to age group. 


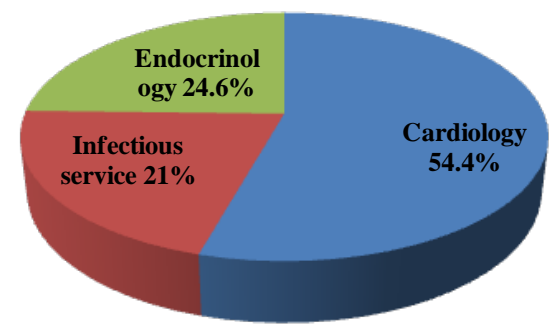

Figure 2. Distribution of patients according to specialties.

in $48.2 \%(\mathrm{~N}=94)$, alcoholism in $28.7 \%(\mathrm{~N}=56)$, smoking in $14.9 \%(\mathrm{~N}=29)$ and the association alcoholism-smoking in $19.5 \%(\mathrm{~N}=38)$.

\subsubsection{Stages of Chronic Kidney Disease}

We noted in Figure 3 that 57 of 195 registered patients as $29 \%$ had end-stage renal disease (Stage V).

\subsubsection{Distribution of Age according to CKD Stages}

In the proportion of 57 (29\%) patients in CKD5, 44 patients were aged between 25 and 64 years as $77.20 \%$. The rest of the results is summarized in Figure 4 .

\subsection{Paraclinical Parameters}

The average calcium and phosphate serum were respectively $1.8 \mathrm{mmol} / \mathrm{l}$ (standards laboratory for normal serum calcium is between 2.2 and $2.6 \mathrm{mmol} / \mathrm{l}$ ) and $1.6 \mathrm{mmol} / \mathrm{l}$ (standards laboratory for normal serum phosphate is between 0.8 and $1.45 \mathrm{mmol} / \mathrm{l}$ ).

Parathyroid hormone and 25-OH vitamin D were not dosed at General Hospital of national reference.

Table 1 summarizes the main measured biological parameters.

\subsection{Therapeutic}

We noted that 120 patients (61.5\%), were taking herbal medicine as shown in Table 2. There was $5.7 \%(\mathrm{~N}=11)$ of patients taking the native vitamin $\mathrm{D}(25 \mathrm{OH}$ vitamin $\mathrm{D})$ and $61.4 \%(\mathrm{~N}=119)$ who had a calcium supplementation as calcium carbonate. 48 out of 57 of our patients with ESRD (24.6\%) in the study are treated with chronic conventional hemodialysis at 2 session of 5 hours per week. 30 patients hemodialysis with arteriovenous fistulas, 8 patients through tunneled catheters and 10 patients with nonpermanent central catheters. Among these patients, there were $12.5 \%$ of death.

\section{Discussion}

This work is the first step of a series. It shows that the epidemiology of chronic renal failure in the General Hospital national reference was 9.6\%. The results were set out overall. This work is limited by the small sample and the absence of multivariate analysis. The variables need to be expanded especially to socio-professional data, risk factors, namely smoking, alcoholism and paraclinical data such as ultrasound and lipid profile. 

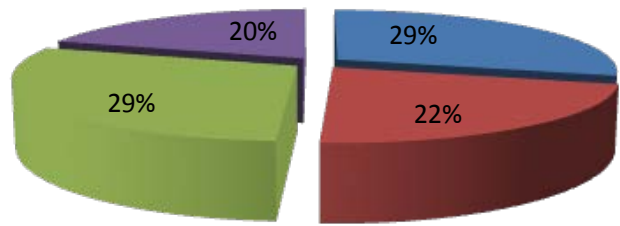

Stade V

- Stade IV

- Stade IIIB

- Stade IIIA

Figure 3. Distribution of patients by stage of CKD.

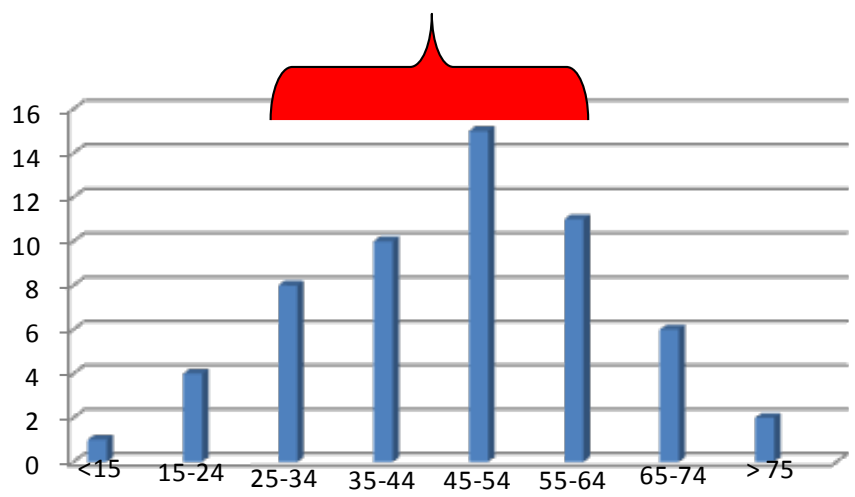

Figure 4. Distribution of age according to CKD stages.

Table 1. Measured biological parameters.

\begin{tabular}{ccccc}
\hline & Hemoglobin $(\mathrm{g} / \mathrm{dl})$ & $\begin{array}{c}\text { Serum calcium } \\
(\mathrm{mmol} / \mathrm{l})\end{array}$ & Uric acid $(\mu \mathrm{mol} / \mathrm{l})$ & $\begin{array}{c}\text { Phosphate levels } \\
(\mathrm{mmol} / \mathrm{l})\end{array}$ \\
\hline Average & 10.5 & 1.8 & 678 & 1.6 \\
Standard deviation & 3.7 & 0.2 & 256.7 & 0.8 \\
Minimum & 05 & 1.4 & 190.0 & 0.7 \\
Maximum & 17 & 2.2 & 1398.0 & 3.4 \\
\hline
\end{tabular}

Table 2. Distribution of patients according to treatment received before hospitalization.

\begin{tabular}{ccc}
\hline Treatment & Number & Percentage (\%) \\
\hline Herbal medicine & 120 & 61.5 \\
Antihypertensive drugs & 25 & 12.8 \\
Antidiabetic drugs & 20 & 10.3 \\
\hline
\end{tabular}

Etiologies of CKD should be incorporated. The average age of our patients was $51.8 \pm$ 16.8 years, ranging from $11-85$ years. In bivariate analysis, the age group of $45-74$ years was the most affected by IRC, as $62 \%$ of cases. It follows that the affected population is young and the results are similar to those found in some studies in Africa [6] [7]; by against the results noted in some developed countries showed that patients affected by IRC have an average age above 60 years [8] [9]. This discrepancy is explained by the fact that in Western countries there is greater access to care, preventive means and could diagnostic performance, a management of patients with faster and more adequate renal failure. 
Sex ratio was 1.4. The same result was observed in most studies [8] [9]. It was noted a higher proportion of patients hospitalized in cardiology (54.4\%). This could be explained by the fact that a large majority of patients in the study were hypertensive and diabetic. Those two pathologies are providers of pericardial and renal dysfunction. Hypertension was found in 129 patients (66.2\%). It is the leading cause of vascular nephropathy and therefore represents one of the main etiologies of CKD in our study. It is as an essential factor of renal disease progression. His balance is essential to stabilize the chronic renal failure. However, we noted that only 25 hypertensive patients $(12.8 \%)$ were on antihypertensive treatment. This low patients treaties is explained by the low socioeconomic level to buy medicines, to poor adherence and local beliefs that would guide patients to use traditional herbal medicine.

Diabetes is the second leading cause. This shows the role of diabetes in the onset of diabetic nephropathy which is one of the causes of CKD in our study. Studies conducted in France and the United States of America had found that the most frequent cardiovascular risk factor was diabetes [8] [9].

These backgrounds are known to be important factors for onset or worsening of CKD [10]-[12].

The primary cause of CKD varies among studies, and can be nephroangiosclerosis [13], diabetic nephropathy or chronic glomerulonephritis [14]. The variation reflects differences in the prevalence of kidney disease among countries.

These increases indicate the severity of the loss of renal function of patients. The end stage renal disease accounted for $29 \%$ of cases. This often explains the delay of initial diagnosis of CKD.

Forty-eight out of 57 of our patients with ESRD hence $84.2 \%$ had received chronic intermittent hemodialysis. The recommended frequency of hemodialysis sessions is three per week. But two sessions per week were set for most cases due to lack of hemodialysis generators. Ideal for vascular access in hemodialysis is that all chronic hemodialysis patients must have an arteriovenous fistula. But in our study, few patients were receiving dialysis arteriovenous fistula by venous. This is due to a faulty technical platform. Kidney transplant was not performed in any of patients in our series.

During our management in hemodialysis $12.5 \%$ of our patients died in a state of poor adherence to lifestyle modifications and therapy and because of severe uremia, advanced kidney disease diagnosed at advanced stage and under dialysis.

Vitamin D are three types of effects on the vascular system: anti-inflammatory, reducing myocardial hypertrophy, inhibition of the renin-angiotensin system. Thus treatment with a form "inactive" of vitamin $\mathrm{D}$, or $25(\mathrm{OH}) \mathrm{D}$ is a new approach for patients with CKD. There was a very small proportion of patient $(5.7 \%)$ was in vitamin D. This is due to the fact that the molecule does not exist on the local market.

\section{Conclusion}

Chronic kidney disease is a silent and long disease. In Chad, at General Hospital of National Reference, the proportion of CKD patient is $9.6 \%$. We noted that $30 \%$ of CKD 
patients were in end-stage renal disease. Despite the growing number of chronic renal insufficient patients in Chad, their care, as in most African countries still suffers lack of specialized structures. Reducing the morbidity and mortality of this condition requires early diagnosis and management of cardiovascular risk factors. This work is limited by the small sample and the absence of several clinical and paraclinical parameters for multivariate analyzes. In future prospects, this study will be extended to other peripheral hospitals in N'Djamena and other cities in order to obtain more representative results.

\section{References}

[1] Jacquelinet, C. and Briançon, S. (2005) Epidemiological and Information Network in Nephrology (Rein): A National Register of Replacement Treatments for Chronic Renal Insufficiency. Bulletin Epidémiologique Hebdomadaire, 37-38.

[2] Said, K., et al. (2013) Troubles minéraux et osseux de la maladie rénale chronique (TMOMRC). Revue Francophone des Laboratoires, 29, 455.

[3] Fouque, D., et al. (2010) Evolution de la prise en charge de la maladie osseuse et minérale des patients hémodialysés en France entre juin 2005 et juin 2008. Néphrologie \& Thérapeutique, 6, 11-20.

[4] Young, E.W., et al. (2005) Predictors and Consequences of Altered Mineral Metabolism: The Dialysis Outcomes and Practice Patterns Study. Kidney International, 67, 1179-1187. http://dx.doi.org/10.1111/j.1523-1755.2005.00185.x

[5] Diouf, B., Niang, A., Ka, E.F., Badiane, M. and Moreira, D.T. (2003) Chronic Renal Failure in One Dakar Hospital Department. Dakar Medical, 48, 185-188.

[6] Yassine, D. (2012) Prise en charge de l'insuffisance rénale chronique terminale en urgence. Thèse Med, Maroc, Fès, 98.

[7] Jarraya, F., Mafouch, Chaibou, L., Yaich, S., Kammoun, K., Kharrat, M., Mrabet, S., Ben Hmid, M., Charfeddine, K. and Hachicha, J. (2008) Prise en charge de l'anémie chez l'hémodialysé en Tunisie. Néphrologie, CHU Hedi-Chaker, Sfax Tunisie. Néphrologie \& Thérapeutique, 4, 517.

[8] United States Renal Data System 2010 Annual Data Report.

[9] Masse, V., Richard, J.B. and Landais, P. (2009) Epidémiologie de l'insuffisance rénale chronique traitée par dialyse.

[10] Berland, Y. and Dussol, B. (2003) Néphrologie pour l'interne, Tome 4. Elsevier, Paris, 386.

[11] Raharivelina, C. and Andriamanantsoa, L. (2004) Insuffisance rénale chronique: La prévention est primordiale dans les pays en développement comme Madagascar. Médecine d Afrique Noire, 15, 245-246.

[12] Ouattara, B., Kra, O., Diby, K., Thot'o, A.S., Ouattara, I. and Ndri, N. (2004) Insuffisance rénale chronique chez l'adulte au CHU de Bouaké. Afr Biomed, 9, 66-70.

[13] Lagoud, D.A., Ackoundoun, N.K.C., Tchicaya, A.F., et al. (2008) Réinsertion profesionnelle et scolaire des patients atteints d'insuffisance rénale chronique et traités par hémodialyse en Côte d'Ivoire. Médecine d'Afrique Noire, 55, 259-264.

[14] Benamar, L., Rhou, H., Guerraoui, M.H., Bakkal, B., Benjelloun, H., Laoud, I., et al. (2003) Cardiovascular Calcifications in Hemodialysis Patients. Prevalence and Risk Factors. Nephrologie, 24, 143-147. 


\section{Abbreviations}

CKD: Chronic Kidney Disease;

CKF: chronic Kidney Failure;

ESRD: End Stage Renal Disease;

GHNR: General Hospital of National Reference;

MDRD: Modification of Diet in Renal Disease.

Submit or recommend next manuscript to SCIRP and we will provide best service for you:

Accepting pre-submission inquiries through Email, Facebook, LinkedIn, Twitter, etc. A wide selection of journals (inclusive of 9 subjects, more than 200 journals)

Providing 24-hour high-quality service

User-friendly online submission system

Fair and swift peer-review system

Efficient typesetting and proofreading procedure

Display of the result of downloads and visits, as well as the number of cited articles

Maximum dissemination of your research work

Submit your manuscript at: http://papersubmission.scirp.org/ 